Article | Special Issue

\title{
Mobility in a Phenomenological Perspective: On Significances of Movement and Quasi-movement in Human Life
}

\section{Li-Qing Qian}

\begin{abstract}
Motion is the fundamental property of all-natural phenomena. However, when human life is concerned, the significance of motion or movement is beyond mere natural process, its concept beyond physical time and space. The genealogical-phenomenological approach is used to indicate that our conception of motion endures a historical transition; meaning, that the conceptual significances with respect to human movement and mobility have always been updated alongside technological progress. With a phenomenological analysis of the historical transition of concepts regarding motion, space, and other correlated notions concerning human existence, we try to show that the extension of these old concepts has been expanded, and the updated concepts are redefined and comprehended in a united but multifaceted way. To achieve this goal, this paper gives out a genealogical survey on some typical instances in the development of human mobility. Such a unified sense-complex of different significances of movement and mobility in human life will contribute to our understanding of the world in a diversified and pluralistic way.
\end{abstract}

Keywords: mobility, space, phenomenology, quasi-movement

\section{Introduction: Theme and Methodological Illustrations}

otion is the most fundamental feature of all natural phenomena. Aristotle explicitly claimed that nature is the principle of motion in general, including all kinds of movements and phenomenal 
changes. ${ }^{1}$ Traditionally, objective motion in general is taken as a basic thesis in natural philosophy, which mainly concerns physical space and time.

However, for objects with consciousness, especially human agents, the significance of motion has to be considered in a more specific way, not only because the human race is a very small species under the concept of object in general, but mainly because phenomena concerning human beings are essentially always beyond mere physical or material interpretations. This essentiality was exposed in detail by John Urry in Sociology Beyond Societies (2000). Urry points out in this book that human mobility is essentially socioontological, which is not quite opposite to, but definitely surpasses, any possible perspective based on modern physics or other natural, scientific investigations.

Even before it became thematic, mobility has always been one of the most evident features of human action. Yet, just like other fundamental factors of human life, it has been overlooked in theoretic reflections, until a sharp change brings it to the spotlight. As a prominent consequence of industrial revolution, human mobility has greatly developed. The industrial revolution also brought forth a brand-new ideal framework of social communication as well as of society. Two centuries later, the industrialinformation revolution introduced a new dimension into human activities, namely, a new configuration in life space created by social networks and mobile technologies. Consequently, with the development of science and technology, the understanding of human movement and mobility has changed time and again, leading to new theoretic reflections.

In philosophy, phenomenological approaches are usually regarded as descriptive methods concerning meanings and essences of things, which are not "hidden" inside but are already manifested explicitly in a certain way. Hence, the point is to appropriately articulate the already-present significance. Concerning the significances of a concept or conceptual system that has been constituted diachronically, a phenomenological analysis must take the historical transition of concepts into account. This does not entail, however, that we have to study such conceptual development by means of historiography; rather, we only focus on the essential features of the genealogy of notion, taking it as an evolution of ideas, with structural changes from simplicity to complexity and with their senses changed from the original into various modified modes. ${ }^{2}$ In this process, formerly constituted significances are preserved as foundations for further apprehensions, and new comprehensions may be developed according to different perspectives

\footnotetext{
${ }^{1}$ Aristotle, Physics, trans. by C. D. C. Reeve (Indianapolis: Hackett Publishing Company, Inc. 2018), 38, 200b11-14.

2 See Edmund Husserl, Logical Investigations, Volume II, trans. by J. N. Findley (London: Routledge, 2001), 159-160
} 


\section{MOBILITY IN A PHENOMENOLOGICAL PERSPECTIVE}

and contexts. On the other hand, a newly formed notion can be "fused" with past understanding into one conceptual term that was used before, and people may regard this expanded concept not as internally split or heterogeneous, but still as a unity.

Husserl called this kind of historical preservation and transition of significances as sedimentation and reactivation. ${ }^{3}$ Unlike Hegel's concept of sublation, which concerns a presupposed single and absolute ideal entity realized in different forms, sedimentation is about the transition of a definite significance into its latent or dormant status within different stages of constitution. Here the term "constitution" can be simply interpreted as an idealistic "architectonics" of the full sense of a historically generated concept. Indeed, most concepts are generated and developed diachronically, with their meanings shifted more or less in their applications. Generally, there are situations where an original concept is accepted or defined for the first time, and further changes in it, which are based on its originality, are taken as derivatives and modifications. Thus, without the originally emergent case of concept $X$, be it well-defined or simply a result of convention, no modified case could be properly grasped as an instantiation of $X$. Conversely, the original or simplest example of $X$ offers us an appropriate point for further cases to be subsumed under X.

The sedimentation of conceptual senses is a result of a formerly constituted unity of significances, and it is the foundation of possibility and validity of our original understanding of a concept. But if some conceptual significance is sedimented within certain constitutions of higher order, it will not function explicitly and may thus be suppressed, neglected, and forgotten by users. Just as the original meaning of the straight line in the Euclidean system is sedimented when the system is axiomatized in the Hilbertian way, the original meaning will only function implicitly or heuristically. In other words, sedimented senses can only be found in a retrospective light that aims at reactivating the origin of validity and comprehensibility of the currently functioning concept. Nevertheless, it is the sedimented that founds the accessibility to the new conceptual framework, and this proves that we can properly make a special type of modification on the sedimented sense to expand a concept. In this perspective, it is valid to continue using the same old term in a new conceptual framework and to regard it as a new starting point for any further modification.

Accordingly, the configuration of a diachronically-expanded conceptual sense-complex seems analogous to what is called "superimposition" in photography. Statically viewed in contemporary

${ }^{3}$ Edmund Husserl, The Crisis of European Sciences and Transcendental Phenomenology, trans. by David Carr (Evanston: Northwestern University Press, 1970), 71.

(C) 2021 Li-Qing Qian

https://www.kritike.org/journal/special issue 2021/qian april2021.pdf

ISSN 1908-7330

(c) $)$ BY-NC-ND 
understanding, every concept looks like a snapshot of the status of its current notion in use, which has been comprehended differently in the past. Dynamically considered, the historically constituted concept is always a diachronically-superimposed unity. The true meaning of the concept neither lies solely on the top layer of the final compound product, i.e., the latest updated interpretation, nor does it completely belong to the original interpretation. Rather, it manifests itself in the unity of all the layers throughout history. The latest phase of constitution may be only related directly to its closest previous phase as modification, but it may also reduce its predecessors into sedimentation. We need to reactivate the significances of former phases under one perspective in order to grasp the historicity and essentiality of this whole diachronic constitution.

The abovementioned general methodology must be applied concretely to our current issue. Simply, the phenomenological investigation of the significance of human mobility is supposed to start from the most fundamental form of human corporeal movement and then extend to the toolassisted motion. But modifications and shifts in experiences of mobility never cease here. The way of judging whether we are studying a case of motion depends on how we understand the idea of motion. For example, if we insist that our mobile lives consist in real movements and relevant corporeal (i.e., kinesthetic or proprioceptive) experiences, then we should ignore the current technologies of virtual reality, since action in a simulated environment is always limited and the sense of experiences is only partially fulfilled. However, if we think that motion merely indicates a change of spatiotemporal position pertaining to an object/subject, then a possible modification of human motion could include all kinds of interactive situations in virtual reality, whether visual only or with limited corporeal movement.

Hence, to explore the multifaceted meaning of human mobility, and to interpret phenomenologically its significance to human life as possibly as we can, a step-by-step constitutive analysis might be feasible. Of course, the genealogical-phenomenological approach is not plainly guaranteed by Husserl's or anyone's dogmata; rather, it makes sense only because the meaning and understanding of human mobility are carried out and gradually developed right in a constitutive way just as many other concepts do-from their original modes to modifications. Thus, this study is divided into five main sections according to the following steps:

1. Corporeal motion: Experiences in bodily movements in space and time

2. Societal motion: A topological view of space and motion in the lifeworld

(c) 2021 Li-Qing Qian

https://www.kritike.org/journal/special issue 2021/qian april2021.pdf

ISSN 1908-7330

(cc) BY-NC-ND 


\section{MOBILITY IN A PHENOMENOLOGICAL PERSPECTIVE}

3. Motion by transportation: Societal motion in the age of high mobility

4. Modifications of positional changes: Quasi-movements in the age of high-tech

5. Modifications of quasi-motion: Mobility in cyberspace

\section{The Original Significance of Human Mobility}

As humans are social animals, human movement is different from that of ordinary physical objects. Phenomenologically, a basic reason is that there is an unreducible part in the significance of sociality in common life, namely, a dimension of subjective and intersubjective experience. ${ }^{4}$ This can be illustrated in two steps:

1) The formation of ideas of spatiality in human lifeworld. As the subjective experiential sense is the bottom layer of social agency, it needs to be discussed at first. However, as mobile agents are mobile objects with agency of cognition, desire, and will, it means that, conversely, we cannot neglect the "objective" constituents within subjective experiences.

For an object, we observe and measure its motion according to its positional changes in outer space. The observation is made possible not only by exact mathematical tools, but first by human capability of following the appearance of movement. In a phenomenological perspective, the objectivespatial significance of an object is originally constituted through sensational data in our perceptive fields, e.g., visual fields, tactile fields, etc. ${ }^{5}$ These fields are units of perceptive materials given through varied series of movements by relevant sense organs such as eyes, head, and limbs, together with kinesthetic or proprioceptive (oculomotor, cephalomotor, etc.) experiential data during the corporeal motion.

Properly speaking, we cannot really see an object just by staring at it all the time, nor can we touch an object merely through a swift contact on surface. With single stimulation, all we can have is some kind of feeling or the consciousness of "something" at most, while this "something" is by no means a real thing or an object in strict sense. A preliminary idea of a genuine object, which differs from mere perceptive data, originates from identification of varied apparent phenomena, the variety of which is realized in different perceptive fields with motive modifications. That is, the proper notion of a thing essentially starts from being watched multiple times, from different perspectives, with its positional changes observed, etc., and it is our body

\footnotetext{
${ }^{4}$ For more specific analysis, see e.g., Edmund Husserl, Cartesian Meditations, trans. by Dorion Cairns (The Hague: Martinus Nijhoff Publishers, 1960), 120ff.

${ }^{5}$ See Edmund Husserl, Thing and Space, trans. by Richard Rojcewicz (Dordrecht: Kluwer Academic Publishers, 1997), 68ff.

(C) 2021 Li-Qing Qian

https://www.kritike.org/journal/special issue 2021/qian april2021.pdf

ISSN 1908-7330

(c) BY-NC-ND
} 
movement that makes all these situations possible. The significance of this object is thus constituted in such an interactively mobile system. Meanwhile, we have also formed the primordial notion of an objective space, which is not understood as a mathematical framework of coordination, but as a unitary place that locates things freely inside. In this way, human mobility and actual motion contribute to the establishment of the idea of an outer space containing objects, and it leads to our most fundamental understanding of the apparent form of nature and our lifeworld.

2) The fundamental understanding of freedom. Agential mobility is a fundamental feature of human, which implies the reality of freedom. Theoretically, the concept of freedom can be described with regard to human mobility as a special kind of modality of subjective localization, which is different from the modality of objective localization.

For an object, every positional change cannot be properly considered without its being observed, being measured, being located. These descriptions remind us that the concept of objective motion is essentially founded on subjective thought and apprehension, no matter whether the object moves "by itself." On the other hand, however, human motion is not entirely passive, because it is enabled by our desire and willing, to which we may assign terms like "faculty" or "competence." Usually, we understand human activities as a series of acts from one's own will, as a phenomenal change with active properties. Only when an agent is unconscious or under restraint, may we regard his/her motion as totally passive. However, in a state of unconsciousness or restraint, there is no agency in the subject; meaning, the human body is regarded simply as an ordinary physical thing. Thus, due to its intrinsic linkage with will and voluntariness, human mobility entails self-determination and potentiality of choice, which make it distinct from the mobility of a common object.

Moreover, our primordial comprehension of freedom is further constituted in daily life through interaction with other people. To communicate, understand others, or accomplish something together, one must act freely with one's body. The idea of freedom is thus confirmed and reconfirmed through this kind of process. In such a dimension of interactivity, sociality is constituted in its authentic sense, which implies the further possibility of estimating and comparing different degrees of freedom.

Of course, we can say that one is able to estimate one's own capability of reaching some goal in a solipsistic view, yet this estimation bears no intersubjective or social significance, and thus without any cultural-objective value. ${ }^{6}$ But when a communal recognition takes place in social life, we can

\footnotetext{
${ }^{6}$ It can be argued whether there is any "objective" or interculturally-comparable value, but this is not our focus. For a defense of this standpoint, see Charles Taylor, "The Politics of 


\section{MOBILITY IN A PHENOMENOLOGICAL PERSPECTIVE}

practically and diachronically synthesize different phases of life period into one unity, with intersubjective identifications and confirmations on social affairs. Through such synthesis, we obtain a common standard of estimation of varied values, and we now know "objectively" what is better and what is worth doing, for the common good.

Besides historically inherited knowledge, people forge their value system through their own social activities, all of which are realized only in movements with characters of sociality. Here we call this kind of motion as "societal motion." With societal mobility, people get in contact not only with their neighbors, but also with strangers and aliens. To some degree, the recognition of an alien is a typical feature of evolution in one's mindset about sociality. Although sometimes people may not accept an alien lifestyle or ideology, such an understanding is still based on a discovery, and the encounter is made possible only through a certain kind of societal motion. With mobility as a societal and intentional capability, we have expanded our cognitive and ethical scope, no matter if such an expansion brings positive results or not.

The analysis in this section indicates that the comprehension of human movement not only enlarges the referential scope of "motion," but also expanded some correlated concepts like space. Furthermore, with the focus transited from physicality to sociality, our understanding of lifeworld and social existence is inevitably involved. Thus, we find that all proper senses in concepts concerning sociality (like "freedom") are inseparable from those in concepts concerning mobility. On the other hand, this reciprocally offers us an updated version of concepts such as motion and space. We can now understand the newly constituted significance not as merely metaphorical, but as a proper layer of this conceptual unity in expansion. Finally, such an update gives out a new ground that enables a concept to get further expanded due to different foci on varied aspects of this sense complex.

In this perspective, experiences of alien contact not only enable us to compare our own ideological frameworks between past and contemporary understanding of space, but also bring out a possible way of understanding the meaning of exploring the unknown. And this is the next landmark in the process of conceptual expansion of human mobility.

Recognition," in Multiculturalism: Examining the Politics of Recognition, ed. by Amy Gutmann (Princeton: Princeton University Press, 1994), 66-73.

(c) 2021 Li-Qing Qian

https://www.kritike.org/journal/special issue 2021/qian april2021.pdf

ISSN 1908-7330

$((c))$ BY-NC-ND 


\section{Insights from Cartography: A Topological View of Life Space and Societal Mobility}

Humans expand their scope of cognition of the world by exploring the unknown terrain, thereby meeting aliens. This spatial information of new places is then recorded and compared with the already known. The product of the unification of spatial records, ${ }^{7}$ together with cultural and experiential information obtained by cartographers along the way, are maps and charts. ${ }^{8}$ Thus, a map reflects not only the cartographer's comprehension but also an era's general ideology.

Humans depicted landscape representations about 30,000 years ago, and the earliest map discovered was about 8,000 years ago. ${ }^{9}$ Maps had been unfamiliar to most civilizations until civilizations dominated vast regions. Thus, the ancient Greeks and Romans made great achievement in terrestrial and celestial cartography as their empires expanded. When Christianity spread throughout the western world, maps were assigned with new significances. This can be seen in the symbolism in medieval cartography, where maps enlarge the principal area of interest and set the perspective based on it. Unlike in realism, the metric property is not crucial in symbolism. Thus, medieval continental or world maps are represented as the body of Christ, with his head on the top of the map as the standard orientation. ${ }^{10} \mathrm{In}$ contrast to this symbolism, large-scale traditional Chinese maps set the orientation with regard to Chinese cosmology, while the earliest Japanese maps might orient west at the top. ${ }^{11}$

Two things need to be noted here. The first one is that human movements in ancient times never brought us merely objective information of a place, because human activities always produce an integrated comprehension of varied aspects. When we move to an unfamiliar place, we do not only see landscapes and geological characteristics. As social animals, people are attracted by all kinds of representations of cultural achievements. Our cosmo-mythological and ethnical conceptions, together with fantasies and imaginations, are all constituents of a narrative of an alien place. An ancient map bears such a synthetized narrative, while a modern scientific map does not. However, it is not because human beings have successfully

\footnotetext{
7 See J. B. Harley and David Woodward eds., The History of Cartography, Volume 1 (Chicago: The University of Chicago Press, 1987), 1.

${ }^{8}$ See Matthew H. Edney, Cartography: The Ideal of Its History (Chicago: The University of Chicago Press, 2019), 1-3.

${ }_{9}$ See Harley and Woodward ed., The History of Cartography, Volume 1, 57.

${ }^{10}$ See Ibid., 288-292.

${ }^{11}$ See J. B. Harley and David Woodward ed., The History of Cartography, Volume 2, Book 2 (Chicago: The University of Chicago Press, 1994), 247.
} 


\section{MOBILITY IN A PHENOMENOLOGICAL PERSPECTIVE}

escaped from the superstitious or prescientific labyrinth; it is because we do not need maps anymore to tell us about those narratives.

The second point is more crucial. When medieval cartography is compared with Chinese or modern European cartography, differences in metrical consideration can easily be seen. To be precise, it is the medieval map without the exact metric information that highlights a special kind of spatial understanding, i.e., the topological conception. The term "topology" here is concerned not with the purely geometric relationship among spatial objects, but with the teleologically-based spatial relationship among cultural objects in our lifeworld. We may regard this topological view as existential instead of mathematical.

Accordingly, the brief touch on cartography serves here as a historical and typical exemplification of the topological view on life space, and it also indicates that the thematic conceptualization of this view should come from our daily experiences. The topological mode of understanding of the world is actually very common in routine life, although one could be unaware of it. Let us consider the ordinary movements in a city or town. If we want to go somewhere familiar, we estimate the time on route, we do not calculate the exact distance. We usually begin with a rough orientation and simply estimate the time with past experiences. If we want to go to a new place around a familiar area, we recall familiar landmarks for basic orientation. Only when the whole place is alien do we use some guidebook or app for the exact location. Normally, streets, corners, shops, and other landmarks are not manifested in our cognition as a strict spatial configuration; instead, they are presented as topological elements, like vertices and lines in graph theory. For ordinary life in a most familiar space, the standard metric is not important, since objects, locations, and orientations are weighted mainly with regard to practical and teleological significances concerned.

Therefore, the topological view concerning human existence is not just a matter of space. Phenomenologically, any comprehension of human mobility must presuppose the possibility of agent movement, that is, human motion as the expected and planned (entworfen) action with corporeality. A planned act, however, depends on the formerly constituted understanding of spatial configuration in one's lifeworld, which is not metric but topological.

But why do we humans use such a point of view instead of a metric one? To put it into Heidegger's terminology, here the only thing that matters is Dasein's authentic way of being in the world, which shows characters like de-distancing (Entfernung) and directionality (Ausrichtung). He writes: "Dedistancing is a circumspect approaching, a bringing near as supplying, preparing, having at hand. But particular kinds of the purely cognitive discovery of beings also have the character of bringing near. An essential

(c) 2021 Li-Qing Qian

https://www.kritike.org/journal/special issue 2021/qian april2021.pdf

ISSN 1908-7330

(cc) BY-NC-ND 
tendency toward nearness lies in Dasein."12 Although Heidegger regards nearness not as a physical-spatial notion but a teleological-practical character based on human understanding of the surrounding world, it is an appropriate perspective for us to grasp the essential point: it is our practical purpose and axiological evaluation of varied activities that guide our way to classify different things and set priorities among them, and this situation determines our authentic understanding in their spatial distribution, which is essentially topological. In other words, one originally locates and draws one's psychological map of the lifeworld with topological tools instead of geometric, because the fundamental mode of human existence is teleological and practical. ${ }^{13}$

In this "existential" perspective, according to Heidegger, our topological "datum points/lines" are selected due to the "nearness" of significance which is originated in our existential understanding, and we always start with these easiest or "nearest" handles to comprehend our surrounding life space and to plan for action and motion inside it.

Contemporary cartography might blot out such a point of view with various standards of map design. But again, it is not because the scientification have successfully found out the unique truth of cartography and wiped out the prescientific way; it is just because the teleological and practical function of maps has changed. The authentic significances of human motion in life space are preserved well in our most ordinary activities, through which we understand surrounding environments as meaningful objects indicating orientations for us with varied significances and teleological weights. Nevertheless, this topology is well exposed in the development of modern technologies and relevant conceptual shifts. It was completely imaginable for those who lived centuries ago that they should be living in a different world with brand new understanding of distance if they could have new transportation with tremendous speed. The realization of this dream, on the other hand, relies solely on our actual progress of mobile technology, of which there comes into sight a great shift in human activity with transportation.

\footnotetext{
${ }^{12}$ Martin Heidegger, Being and Time, trans. by Joan Stambaugh (Albany: State of New York University Press, 1996), 98.

${ }^{13}$ One may notice that Heidegger implies that the topological understanding of space is more original, as well as our movements in this regard, but we still take it as a conceptually expanded case. This seeming contradiction is due to two different perspectives: one is existential, another is conceptual. An existentially more fundamental notion does not entail its conceptual fundamentality. Here we are satisfied with merely pointing out the conceptual history in geometry on notions like line, dimension, etc.
} 


\section{MOBILITY IN A PHENOMENOLOGICAL PERSPECTIVE}

\section{Significances and Consequences of Human Motion in the Age of High Mobility}

As Urry noted, leisurely walking and pedestrian touring are typical ways of modern life. ${ }^{14}$ However, these activities emerged with many correlated factors. One of them resulted from the industrial revolution, which has enhanced greatly the power of transportation. Another important factor may be brought by capitalism, which emancipated man from everyday routines with high productivity and commercial economy. These factors, on one hand, relieved people from exhausting labor of little efficiency and made human movements detached from corporeality, so that people could have leisure to rejoin in movement for themselves. On the other hand, the development of technology, especially of transportation, enabled people to reach much farther than before, not as members with official businesses, but as free individuals. In this perspective, a pedestrian action or a long trip by transportation in the last two centuries indicates that everyday movement is gradually relieved from a usual means of livelihood; the walk may well be an enjoyment or some kind of spiritual training in leisure time. With such a point of view on motion, people update their comprehension of the world and themselves. This section aims at sketching out an interactive and reciprocal relation between our conceptual frameworks and their technological products in respect of societal motion.

1) The continuous change in social-spatial topology. We have already interpreted the concept of Heideggerian de-distancing and directionality as topologically shifted characters of human existence with regard to spatial cognition. It entails that the topological structure of spatial understanding can keep on changing with the general framework of human thought.

Long before the proper metric of space and time was used in the civilized community, people had known well of "far" and "near" through corporeal movement. Far destination would cost more time and energy, which can be corporeally and mentally experienced and objectively observed with regard to the change of environment and luminosity. Moreover, the estimation of distance depends solely on our subjective apprehension through time consumed and degree of fatigue in travelling. In light of this, it has been easier for people to find out a sharp change in understanding geographical relationships after the industrial revolution. As Heidegger said, with the emergence of trains, buses, and radio transmission, people may regard a spatially far place as quite near and somewhere close by as very distant. In this view, a distant site will present its "nearness" if there is an easy way to reach it. Heidegger does not take this as merely a difference

${ }^{14}$ See Urry, Sociology Beyond Societies, 52.

(c) 2021 Li-Qing Qian

https://www.kritike.org/journal/special issue 2021/qian april2021.pdf

ISSN 1908-7330

(c) $\mathrm{BY}-\mathrm{NC}-\mathrm{ND}$ 
between different views; rather, it is a matter of competitive paradigms, i.e., the scientific versus the existential. Modern perspectives may support the former over the latter, but Heidegger argues that the existential understanding of space and distance is original and authentic. ${ }^{15}$

Thus, a topological view on life space is genetically prior and fundamental to all kinds of measure and calculation. It explains why and how humans have changed their views and attitudes towards the "same" world, topologically altering it. One can say that there is never one world, but always many different worlds, which are "created" through our understanding and conceptual framework. One crucial alteration in current era is the emergence of a new topological view of society, namely, society as a network.

2) Societies integrated as a global network. When the first railway network was designed in 1838 in Germany, most people had no idea of it, and even described it as something strange like a spider or a labyrinth. Later in the second half of the $19^{\text {th }}$ century, railway networks have become part of European and American life, and this formed a new kind of understanding of society's self-recognition as a net. ${ }^{16}$ The concept of net has many characteristics, ${ }^{17}$ but let us focus on two points.

The first one is de-centralization. According to Heidegger, humans live in the world by understanding surrounding objects as referential beings in their activities. The function of such reference constitutes a united structure of the whole world, which finally renders the worldliness as a referential context. ${ }^{18}$ In this view, objects that serve as referents of significance function as orientators. When considered on the larger scale, whether in the view of geopolitics or of socioeconomics, people still use such orientators, making the most significant things fundamental locators. It entails, however, that there are one or more "centers" in our existential activities. All these centers must be put into a higher order configuration, and we need to establish a correlation structure among them. This yields a network pattern in modern lifeworld.

It is notable that the network structure never weakens the locational function of our daily referential framework, but it does diminish the importance of traditional centers and the significance of centrality per se. It is mainly because the network is enabled by high mobility and efficiency of production so that the material and informational exchanges can be very frequent and flexible, which have led to rearrangements of all kinds of

\footnotetext{
${ }^{15}$ See Heidegger, Being and Time, 98-102.

${ }^{16}$ See Jürgen Osterhammel, Die Verwandlung der Welt: eine Geschichte des 19. Jahrhunderts (München: Verlag C. H. Beck, 2010), 1011.

${ }^{17}$ See Jonas Larsen, John Urry, and Kay Axhausen eds., Mobilities, Networks, Geographies (Burlington: Ashgate Publishing Company, 2006), 11.

${ }^{18}$ See Heidegger, Being and Time, 86-88.
}

(c) 2021 Li-Qing Qian

https://www.kritike.org/journal/special issue 2021/qian april2021.pdf

ISSN 1908-7330 


\section{MOBILITY IN A PHENOMENOLOGICAL PERSPECTIVE}

distribution and accumulation according to varied concrete situations. It is unnecessary to proceed with this topic, which scholars have already studied for centuries. Yet it should be noted that when people have changed the ideology on centralization, there comes a series of consequences in understanding our position in the world, including the problem of home, of the relation between city and suburb, between the native and the foreign, even between human and nature.

The second characteristic is interrelation and interdependence. By the end of $19^{\text {th }}$ century, humans have greatly benefited from networks of railway and maritime commerce, while the invention of the telegram and the radio created a new spatial dimension that has incredibly de-distanced human beings. For the first time in history, people realized that the communal life in a globe is not merely imaginable; with highly efficient transportation available, people are now not only connected with others economically, but also mentally and corporeally. Humans used to live in a relatively small areas that are organized in a centralized way, but now one might have many "homes" in different senses. However, a more complicated structure of social life must bring about more complicated understanding and arrangements of our existence. As we are confined to a unique physical space-time, we must plan for everything in a more efficient style.

3) Life with calculation and exactness. Critics of modernity have described it as "dimensionally compressed." They have called it "formal rationality" (Max Weber), "one-dimensionality" (Herbert Marcuse), "instrumental reason" (Frankfurt School). All these expressions point to the same character of modernity, i.e., the calculation on everything by means of de-qualification and de-differentiation. A moderate summary of modernity given by Giddens indicates that with the increase of knowledge people will create new risks that have hardly been predicted and are difficult to calculate. ${ }^{19}$ There are many reasons of such kind of computationalism, ${ }^{20}$ such as the rise of industrial civilization.

The essential difficulty in financial and insurance market leads to an interesting paradox: people appeal more and more to calculation and try to universalize it in daily life. We neither proceed to analyze or resolve the paradox in this computationalism, nor are we interested in judging it from an

\footnotetext{
19 Anthony Giddens and Christopher Pierson, Conversations with Anthony Giddens: Making Sense of Modernity (Cambridge: Polity Press, 1998), 104.

${ }^{20}$ I borrow this terminology from philosophy of mind to signify the trend of general quantification and process of quantified comparison in modern life. However, the idea of quantifying and comparing different qualities was not a modern invention. It can be traced back at least to a medieval debate on the essence of motion, i.e., the topic of forma fluens vs. fluxus formae, which are not pursued here.

(c) 2021 Li-Qing Qian

https://www.kritike.org/journal/special issue 2021/qian april2021.pdf

ISSN 1908-7330
}

$(\mathrm{Cc}) \mathbf{B Y - N C - N D}$ 
axiological or ethical point of view. The only thing to be noticed here is its significant relation to human life with high mobility.

On one hand, economical and industrial progress with high mobility has brought us with much more materials than centuries ago, which enabled us to develop varied methodologies of mathematical modelling. This is a theoretical condition for the globally fashioned computationalism. Besides, there are much more places and works accessible to us than before, and we can make decisions in a relatively exact way. No matter for what purpose, decisions with precise calculation are superior to non-quantified estimations on the general scale, which is coherent with the whole system of material exchange.

On the other hand, computationalism has exerted a feedback impact on our daily life. The idea of general quantification has penetrated every detail in modernity. If we use cartography again as an example, it can be seen that modern maps are all based on precise measurements with standard metric and the objects are marked entirely as physical-spatial entities according to a proper scale. A map used to bear varied significances, but now it is simplified as a mere quantified indicator. Even in our trips for leisure, we may still calculate everything with a map, especially time and expense.

Conservative critics usually regard this kind of phenomena as a decline of human understanding, imagination, and creativity. Whether it is true or not, the focus is on a neutral description of transition of human ideas. Some scholars have noticed that developments in computation and calculation are bringing us a new world order. ${ }^{21}$ No matter this update of order has a good or bad result, one thing is certain: our life is changed once and for all, and there seems no way back. As one of the most important characteristics of the age of social network, this kind of computationalism is also existential, and it has already been internalized as our most intimate pattern of cognition and organized practice in daily life, ruling our societal motion.

\section{The Modified Significance of Physical Motion: Objective Quasi- Movements}

We have discussed the significance of human mobility in a step-bystep process of constitutive analysis, trying to show the way in which the societal motion gains its full sense. It is to be noted that in daily life whether we move by our feet or by any mode of transportation, we actually move our bodies in proper sense. Thus, all kinds of societal mobility mentioned in the

${ }^{21}$ Monika Büscher, John Urry, and Katian Witchger eds., Mobile Methods (New York: Routledge, 2011), 14.

(C) 2021 Li-Qing Qian

https://www.kritike.org/journal/special issue 2021/qian april2021.pdf

ISSN 1908-7330

(cc) BY-NC-ND 


\section{MOBILITY IN A PHENOMENOLOGICAL PERSPECTIVE}

previous sections substantially concern the actual motion of human corporeality, which is the original and authentic type of human motion. Now let us proceed to some essentially modified circumstances.

Phenomenologically, when an original mode of certain species of intentionality is properly reflected and recognized, we may find some modified modes in the same species, which are founded on the original one. For example, in the species of sensible intuition, the original mode of act is perception, and there are modified modes like imagination, recollection, expectation, etc. All these modifications are founded on ordinary perception of physical objects, because they are essentially indirect ways of bringing objects into sensible intuition but with their materials reconstituted and reorganized from originally given data in perception. The concept of motion, in the same light, whether understood physically and societally, also has its modifications. Yet, the way of modification depends on how we comprehend and interpret the concept.

As is said in the first section, the preliminary significance of movement resides in the constitution of data given in multiple sensual fields of corporeality, and the correlate of sensual experiences is the positional change of the agent regarding its location in the surrounding environment. However, positional change is also constituted in the synthesis of perceptive data as a result of objectivation. By and large, motion as a change in spatial status is always constituted from two kinds of subjective elements: perceptive fields with data and kinesthetic fields with data. From this point of view, the operation of modification lies in considering the degree of fulfillment of intention regarding these elements.

Let us consider the technology of 3D IMAX. Anyone who has experienced this cinematic achievement has surely been impressed with slogan: "watch a movie, or be part of one?" This "being part of" obviously means some kind of being located within or "projected into" the movie scene. Phenomenologically, we feel like being there because the apperception of data in visual and auditory fields is close to that in the real world. But this approximation is by no means identity, since there is always a gap between reality and the immersive experience. And because of this gap, we are at the same time conscious about not really being part of the movie. To be precise, when watching a 3D IMAX, we may have similar oculomotor experiences as is in real situations, but there is hardly any other bodily kinesthetic experience. Without sufficient corporeal constituents, we will only recognize it as an apparent movement instead of a real one.

Husserl used the concept "quasi-movement" to describe a certain kind of non-objective motion of an object, which can be roughly understood

(C) 2021 Li-Qing Qian

https://www.kritike.org/journal/special issue 2021/qian april2021.pdf

ISSN 1908-7330

(cc) BY-NC-ND 
as the phenomenological version of "apparent movement" in physics. ${ }^{22}$ By using "quasi-movement," together with "quasi-location" and "quasidisplacement," Husserl tries to depict an entirely subjective region of preobjectively synthesized data that are given to our consciousness as mere "presentational contents." However, according to Husserl's methodology, the difference between quasi and proper movement depends solely on the stage of constitutive process. In other words, a proper movement is nothing but a completely constituted quasi-movement with fully objective sense. Conversely, a quasi-movement always lacks some significance or elements of objectivity so that we could not properly apprehend the phenomenon as a real movement of an object. In this perspective, the concept of quasimovement can be expanded with a greater extension; namely, except for real movements of physical objects, all kinds of positional changes in perceptive fields can be regarded as quasi-movements.

Nevertheless, this interpretation seems to imply that we can hardly regard quasi-movement as the modification of real movement, because the real and objective is constituted from the previous stage of apparent change. Consequently, if we want to demonstrate that the experience of quasimovement in cases like watching a movie is really the modification of real motion, it must be pointed out that a) our current focus is merely on a special class of quasi-movement brought by audiovisual techniques, not quasimovement in general; and b) this special kind of quasi-movement is not a subjective level prior to objective constitution; rather, it is deliberately designed as a simulation or imitation of real motion in order to bring us lively experiences. That is, audiovisual technologies present us with something objective, and we only need to modify our attitude towards it, as if we were part of the movie, as if we were really moving in another world, etc. The attitude of "as if" is usually classified into the intentional act of imagination, but we should notice the passive part in this active operation, i.e., to realize how much audiovisual technologies have contributed to stimulate our fantasies.

The development of such technologies does not entirely depend on physical science. For all kinds of video shooting, one crucial thing is the position and orientation of cameras, especially in their motion. As a remarkable achievement in the age of high mobility, film, together with its progenies, is based on the study of viewpoint in motion. And this must be further traced back to human sight in the dynamic situation, so the ultimate foundation of cinematic technology is linked with human mobility.

When the ocular viewpoint is replaced with a camera, people can step back and simply watch the motion: they do not have to move by themselves

22 See Husserl, Thing and Space, $83 \mathrm{ff}$.

(c) 2021 Li-Qing Qian

https://www.kritike.org/journal/special issue 2021/qian april2021.pdf

ISSN 1908-7330

(cc) BY-NC-ND 


\section{MOBILITY IN A PHENOMENOLOGICAL PERSPECTIVE}

or by transportation; they can now leave the real movement aside and just watch it. On the other hand, however, they are not completely cut off from motion. Hence, this type of motion can be seen as preserved in a specially modified way, that is, people participate in this modification not with their whole corporeality, but only with a part of it. Through these cognitions and recognitions, we can enjoy the flow of images on a static screen as the objective quasi-movement.

Although 3D IMAX technology is astonishing, it is not so far away from ordinary film, because self-projecting is just an advanced stage of watching, without essential improvement. Hence, we may classify all kinds of traditional audiovisual techniques into one type. Phenomenologically, a more radical invention concerning mobility is virtual reality (VR). Unlike ordinary video, a standard VR scene is 3D-panoramic from the user's viewpoint. It means we must participate with something more than oculomotor and slightly cephalomotor acts; thus, we enjoy it with almost all kinds of corporeal motion.

VR is closer to reality than other types of visual techniques with respect to the significance of quasi-movement; however, it is still distant from real or objective motion. It is not because the corporeal movements in VR lack liveliness, for we can imagine that super machines like those in the movie Matrix could offer us a quite vivid world with every kind of corporeal movements available, but still know it is virtual. In other words, we are not detached from our reality in VR, and we do not lose the fundamental disposedness (Befindlichkeit) of being in the (real) world. ${ }^{23}$ What we are experiencing in VR is a mixed world situation, with a default belief of still being and acting in the real world as a base while perceiving the simulated objects in the subordinate world with liveliness.

The mixed or compound experiential feature given out by VR is a result of a synthesis of real movement and objective quasi-movement. As a further step of high mobility, it has inherited all the merits of modern technologies of transportation, and has greatly expanded the scope of accessibility. It even crossed the boundary of reality as the traditional default point of human existence. With the recognition of the significance of quasimovement, we are gradually updating the understanding of disposedness and other existential features, just as when people moved from an isolated

\footnotetext{
${ }^{23}$ See Heidegger, Being and Time, 126ff. Accordingly, there is an ontological difference between VR and the equipment in Matrix. In the movie, which was inspired by the famous thought experiment "brain in a vat," the equipment sets a complete and coherent structure of world experience in a simulated space, and the subject is entirely disposed within this simulation. Protagonists are thus not projected into a sub world or a fake world, but simply and totally into another world. Conversely, Matrix does not present us a virtual reality; rather, it gives out an alternative reality.

(c) 2021 Li-Qing Qian

https://www.kritike.org/journal/special issue 2021/qian april2021.pdf

ISSN 1908-7330
}

$((c))$ BY-NC-ND 
area to a modern society. No matter what Heidegger said about humans' homelessness and uprootedness, we can always change our attitude towards the new situations of disposedness, and take the newly modified way as our start point of understanding the world. In other words, it does not mean we have to challenge the classic dogmata of existential phenomenology or to deny the fact of "having forgotten the being as such"; we can just preserve these diagnosis records and leave them aside, then focus on what has been created as the new facticity.

Up to this section, we have seen that the significance of motion/movement endures a diachronic shift with the historical change of our life, and the history of its constitution can be identified as a process of modification, first in its original sense as corporeal movement, then as movement by transportation, finally as a quasi-movement in a recorded or even virtually-presented appearance of motion, which only partly coincides with our experience of real motion. It shows that there is a continuous change of relationship between subject and its surrounding space, or to say, the significance of mobility has been converting step by step from "us coming into the space" to "the space being brought to/in front of us." And the conceptual shift of space will reciprocally affect the meaning of motion.

\section{Modification of Quasi-Movement: Significances of Mobility in Cyberspace}

Quasi-movement, whether interpreted as subjective or objective, is eventually about physical changes in space. Correspondingly, there is still another dimension of human mobility, i.e., that of social life. But just as the societal understanding originates from primordial experiences of physicality, so is the modification of quasi-movement with regard to sociality.

When the relation between agents and space is changed by high technology, which, to some extent, brings the space and its change right in front of us, we can expect a further modification on the significance of space per se in a valid way. One of the purposes of those inventions concerning objective quasi-movement is to blur the ontological gap between the real space and the virtual space, which respectively belong to different worlds. Besides, from the intersubjective point of view, with audiovisual techniques available to people, we face the simulated space not as individuals, but as a group or community sharing common experiences. Therefore, a social space can be realized as a "quasi-physical" space, and the time-space compression in modern society also has a direct impact on this kind of situation. ${ }^{24}$ In this light,

${ }^{24}$ David Harvey, The Condition of Postmodernity: An Enquiry into the Origins of Cultural Change (Cambridge: Blackwell Publishers, 1989), $284 \mathrm{ff}$.

(c) 2021 Li-Qing Qian

https://www.kritike.org/journal/special issue 2021/qian april2021.pdf

ISSN 1908-7330

(cc) BY-NC-ND 


\section{MOBILITY IN A PHENOMENOLOGICAL PERSPECTIVE}

such a social space will offer us a good viewpoint to take both physical and social features of space and motion into account, in which we may reach to an appropriate modification of these concepts. Let us look at the instance of cyberspace.

Cyberspace was first understood as a virtual realm created by mere links between computers, devices, routers, etc. It is not the Internet itself, but a creation produced by the Internet's infrastructure. We can analogously call it as a "place" or "space," yet the phenomenological sense behind this analogy is nothing but another step of modification of significance and a further conceptual expansion. We have seen from previous sections that the concept of motion, together with that of space, has been gradually shifted and expanded, with the multifaceted sense-complex "fusing" with formerly constituted significances into a more complicated unity.

Just as the idea of motion can be extended to the social realm and can assimilate a contemporary type of quasi-motion into it, the conceptual expansion of space, as a correlated circumstance, may be accepted as well, without contradiction to its original sense. As was said in previous sections, the concept of space, distance, as well as motion, can be comprehended topologically. Since the topological understanding has already paved the way for making all kinds of interpretation of things and their connections isomorphic to a graphical model (in which the notion of cyberspace locates), some physical and substantial features of space could thus be neglected or modified. In a word, like the constitutive process from a metric space to its topological or graphical interpretation, we can also enjoy a brand-new view of space in general while keeping the original senses of it in mind.

In cyberspace, we can talk about a remodification of objective quasimovement in a valid way. That is, the quasi-motion, in which the simulated space is brought to us, can be further modified in the sense that the representation of other persons can be brought to us together with a special type of space. And our existence is actually reaching out to each other in this information space, though not with our corporeality transported physically. ${ }^{25}$

However, if cyberspace is taken as a special kind of space, then what about motion and human mobility in it? Obviously, the audiovisual techniques such as VR still provide us with a special kind of motion, though in a simulated way. Yet in cyberspace, there is nothing in movement or in quasi-movement, except for electrons and photons running in wires and servers.

To explain the problem, first we must understand that modification in general is not a mere reconfiguration of semantic structure, as if it could

\footnotetext{
${ }^{25}$ Technically, when the metric is defined as a graph-theoretic one, and the exact distance is determined and calculated according to other topological features, the modified pattern of spatial comprehension can be used to describe this abstract dynamic space.

(c) 2021 Li-Qing Qian

https://www.kritike.org/journal/special issue 2021/qian april2021.pdf

ISSN 1908-7330
}

(c) $)$ BY-NC-ND 
always be traced back to its original form. It is true that we can exert a phenomenological "reverse engineering," according to the process of constitution of the intentional object, but we do it only by analyzing its significance in historical transition, with some part of its essential structure preserved while altering the rest. Just as what Husserl saw on the arithmatization of geometry, which emptied the spatial meaning and transformed the geometrical into numerical configurations and algebraic structure, ${ }^{26}$ some types of modification may completely change the ontological properties of an object.

As for the transformation or modification of space and motion, it requires us to focus on some invariant features in our flexible understanding of these concepts. On one hand, people have learned that space is essentially a complex of positional relations among objects. A physical space, or a geometric space, or even a space in metaphoric sense, is a particular instantiation in this general class. Furthermore, the notion of position is not only of the objects, but also relative to them with regard to its significance. If the object is understood physically, a position means the location of the object in space-time. And if the object is comprehended socially or culturally, such as a person, we may take that person's position as the social status or social rank in the cultural hierarchy. On the other hand, motion is always a counterpart of space, which entails that we understand motion in the same perspective as we understand space and position. When the space is interpreted essentially as a positional complex, motion will correspondingly and simply refer to the change in such a complex within a segment of time. For example, we usually understand social space in this sense, where the concept of space is understood analogically.

In the case of cyberspace, therefore, the significance of motion can be seen as realized in a degenerate status that was transformed from quasi-motion as its previous stage. We preserve the essential senses of positions and their relations, though interpreted in a different paradigm, and remove all the physical semantics. We understand ourselves as individuals in a special space of sociality, in which all kinds of communications are well preserved and become more efficient. In a net community, we can get close to someone or feel isolated, be active or be passive, follow the hot topics, make a group, or hold a conference. We also apprehend in this way what "nearness," "directionality" and "de-distancing" could mean in cyberspace. All the verbs we use to describe our online routine are taken from reality as analogs, but the possibility of such an analogy is founded on a systematic modification of our understanding of space and mobility. Hence, despite that the original senses of these concepts disappear in cyberspace, they still leave their traces

${ }^{26}$ See Husserl, The Crisis of European Sciences, 44.

(c) 2021 Li-Qing Qian

https://www.kritike.org/journal/special issue 2021/qian april2021.pdf

ISSN 1908-7330

(cc) BY-NC-ND 
and impacts so that we could continue to shape our understanding of life in cyberspace with the modified and expanded conceptual framework. This could be the basic framework we use to make sense of numerous online "movements" on social media today.

All in all, cyberspace, as a typical instantiation of a modified social space, presents us with a new idea of our orientation in the lifeworld. With new technologies like cyberspace available, we have obtained a multifaceted comprehension of mobility, which combines our daily corporeal motion and incorporeal online social action into one unity. Now it is reasonable to state that the concept of mobility must be expanded into a more comprehensive configuration, with plural but unified significances, so that we can apprehend the current lifeworld in a better way.

\section{Conclusion: A Historically Superimposed Image of the Concept of Mobility}

Through the progress from video to internet, from traditional media to social media, we know that we are much less confined to physical spaces than ever. We have also discovered the separation between motion and embodiment, because the technical developments after industrial revolution are great enough to shake our traditional beliefs. ${ }^{27}$ All these lead to a sharp conversion of our comprehension of mobility.

An important lesson we may learn from history is that the world is becoming more and more complicated, not only in materiality, but firstly in the sense of ideality. Almost all concepts have already been assigned with new meaning, with many not seen as split and different conceptual entities with the same "strings," but rather regarded as unified sense-complex with different layers of significances. This layer pattern, though seems geological, is better interpreted with a schema of superimposition in the light of phenomenological-constitutive analysis.

Human mobility is an exemplification of this schema. Mobility, together with concepts like space and distance, has been "superimposed" with their updated significances over the past meanings for centuries. We have expanded our scope of comprehension of these notions due to technological and ideological developments, from the existential-topological interpretations to the mathematical-metric ones, and from their primordial modes to varied quasi modes. In this process, we have not only extended our understanding of the concepts of space and motion, but also have changed our lifestyle in reality. Mobility and human life are so intertwined; thus, "how

\footnotetext{
${ }^{27}$ It should be noted that there are also technologies of extended embodiment, which, to some extent, do expand our corporeal capability and mobility. However, due to the limitations of this paper, I cannot discuss them in detail here.

(c) 2021 Li-Qing Qian

https://www.kritike.org/journal/special issue 2021/qian april2021.pdf

ISSN 1908-7330

(c) BY-NC-ND
} 
mobile lives are conceived of in theories, models and technologies shapes how they are lived and vice versa: plans, rules, theories, models, and technologies become what they are in and through lived mobile practices." 28 Now there is a more complicated and pluralistic understanding of "nearness" and other existential notions, concerning their geographical, instrumental, and cyberspatial senses, and we can plan for our lives with calculation on all these factors, comparing their weights in respect to different conditions. In this way, our real life in this age of high mobility, as well as the reality itself, is pluralistically constituted and keeps diversifying.

Institute of Philosophy, Shanghai Academy of Social Sciences, China

\section{References}

Aristotle, Physics, trans. by C. D. C. Reeve (Indianapolis: Hackett Publishing Company, Inc., 2018).

Büscher, Monika, Paul Coulton, Christos Efstratiou, Hans Gellersen, and Drew Hemment, "Connected, Computed, Collective: Smart Mobilities," in Mobilities: New Perspectives on Transport and Society, ed. by Margaret Grieco and John Urry (Burlington: Ashgate Publishing Company, 2011).

Büscher, Monika, John Urry, and Katian Witchger eds., Mobile Methods (New York: Routledge, 2011).

Edney, Matthew H., Cartography: The Ideal of Its History (Chicago: The University of Chicago Press, 2019).

Giddens, Anthony and Pierson, Christopher, Conversations with Anthony Giddens: Making Sense of Modernity (Cambridge: Polity Press, 1998).

Harley, J. B. and David Woodward eds., The History of Cartography, Volume 1 (Chicago: The University of Chicago Press, 1987).

The History of Cartography, Volume 2, Book 2 (Chicago: The University of Chicago Press, 1994).

Harvey, David, The Condition of Postmodernity: An Enquiry into the Origins of Cultural Change (Cambridge: Blackwell Publishers, 1989).

Heidegger, Martin, Being and Time, trans. by Joan Stambaugh (Albany: State of New York University Press, 1996).

Husserl, Edmund, Cartesian Meditations, trans. by Dorion Cairns (The Hague: Martinus Nijhoff Publishers, 1960).

28 Monika Büscher, Paul Coulton, Christos Efstratiou, Hans Gellersen, and Drew Hemment, "Connected, Computed, Collective: Smart Mobilities," in Mobilities: New Perspectives on Transport and Society, ed. by Margaret Grieco and John Urry (Burlington: Ashgate Publishing Company, 2011), 140.

(c) 2021 Li-Qing Qian

https://www.kritike.org/journal/special issue 2021/qian april2021.pdf

ISSN 1908-7330

(cc) BY-NC-ND 


\section{MOBILITY IN A PHENOMENOLOGICAL PERSPECTIVE}

The Crisis of European Sciences and Transcendental Phenomenology, trans. by David Carr (Evanston: Northwestern University Press, 1970).

Logical Investigations, Volume II, trans. by J. N. Findley (London: Routledge, 2001).

Thing and Space, trans. by Richard Rojcewicz (Dordrecht: Kluwer Academic Publishers, 1997).

Larsen, Jonas, John Urry, and Kay Axhausen eds., Mobilities, Networks, Geographies (Burlington: Ashgate Publishing Company, 2006).

Osterhammel, Jürgen, Die Verwandlung der Welt: eine Geschichte des 19. Jahrhunderts (München: Verlag C. H. Beck, 2010).

Taylor, Charles, "The Politics of Recognition," in Multiculturalism: Examining the Politics of Recognition, ed. by Amy Gutmann (Princeton: Princeton University Press, 1994).

Urry, John, Sociology Beyond Societies: Mobilities for the Twenty First Century (London: Routledge, 2000).

(C) 2021 Li-Qing Qian

https://www.kritike.org/journal/special issue 2021/qian april2021.pdf

ISSN 1908-7330

(c) BY-NC-ND 